\title{
O discurso de Luiz Ruffato em Frankfurt: polêmica, recepção inicial e paradigmas em disputa
}

No dia 8 de outubro de 2013, a 65 edição da Feira do Livro de Frankfurt (FLF), na qual o Brasil foi o país homenageado, contou com o discurso de abertura proferido pelo escritor brasileiro Luiz Ruffato. ${ }^{2}$ Constituído de 20 parágrafos nos quais o autor faz uma crítica das contradições e desigualdades sociais brasileiras, a repercussão do texto foi imensa, com manifestações favoráveis e contrárias circulando em jornais, blogs e redes sociais imediatamente após a divulgação das opiniões expressas pelo autor na ocasião.

Essa proliferação de textos, opiniões, pequenos artigos ou comentários e especulações colocou em evidência o processo de reconfiguração, transformação e, inclusive, das novas possibilidades do debate cultural no campo da literatura, no contexto digital. ${ }^{3}$ Ao mesmo tempo, aponta para uma de suas faces mais dinâmicas e menos especializadas, na medida em que deixa de constituir-se num debate de "poucos" para "muitos", visto que tais formatos proporcionam maior possibilidade de interação por parte do público em geral. Nisso, difere parcialmente do processo que, como lembra José Luís Jobim (2012), colocou a crítica no âmbito da indústria cultural, anteriormente, especialmente a crítica que se publica em jornais e revistas de grande circulação, apesar de seu espaço ser cada vez menor no cenário recente.

\footnotetext{
${ }^{1}$ Doutor em Letras e professor da Universidade Estadual da Paraíba (UEPB), Campina Grande, PB, Brasil. E-mail: alveswanderlan@yahoo.com.br

${ }^{2} \mathrm{O}$ texto integral do discurso de Ruffato na FLF pode ser lido em: 〈http://goo.gl/zB7Zvp >. Acesso em: 12 abr. 2016. Por sua vez, o vídeo com o discurso está disponível em: <https://www.youtube.com/watch?v=tsqcziX5_6E〉. Acesso em: 20 dez. 2013. Agradecemos à Laeticia Jensen Eble, que conseguiu o vídeo junto aos organizadores da FLF e disponibilizou-o para acesso público.

${ }^{3}$ Outro aspecto importante a esse respeito é que muitas das manifestações imediatas em relação ao discurso de Ruffato apareceram em redes sociais, especialmente o Facebook - como se verá em algumas citações apresentadas neste texto -, meios que abrigam gêneros textuais não acadêmicos, muitas vezes informais. Nesse sentido, a própria consideração de tais críticas por nós, neste estudo, requer um olhar delicado e, em certa medida, diferente do olhar sobre um artigo científico, pois se trata de textos que, em geral, estão mais explicitamente próximos das subjetividades de seus autores e de momentos particulares desse debate. Assim, representam, por vezes, impressões mais imediatas e potencialmente menos filtradas pelas políticas subjacentes aos debates acadêmicos nos formatos expressos em textos publicados em veículos institucionalizados (revistas acadêmicas, por exemplo). Seu tratamento requer um olhar respeitoso que, no entanto, não nos impede de lê-los criticamente.
} 
Um primeiro aspecto relevante a respeito do evento envolvendo Ruffato em Frankfurt foi, justamente, sua capacidade de provocar discussão num campo cujos debates geralmente se restringem ao âmbito acadêmico, como é a literatura no Brasil. Mas tal fenômeno também está associado ao papel econômico da feira, e não apenas ao fenômeno literário, se bem que, para sermos rigorosos, é preciso lembrar que há algum tempo o literário e o econômico não se separam mais (Jameson, 1991; Ludmer, 2007; 2010).

Tomada em sua constituição, isto é, enquanto estrutura e acontecimento que, por definição, todo discurso é (Pêcheux, 1990), a fala de Ruffato colaborou para colocar em circulação certas tensões que marcam os discursos sobre a sociedade brasileira contemporânea. Ao mesmo tempo, apontou para um conjunto de disputas entre paradigmas epistêmicos e analíticos que orientam o pensamento crítico sobre o presente não só no Brasil, mas também na América Latina. Esse discurso também é emblemático de um processo que talvez aponte para a emergência de uma nova cultura no campo literário e artístico.

\section{A textualidade da polêmica}

Um primeiro traço que marca o discurso de Ruffato na abertura da feira é sua imediata transformação em polêmica. Ao observá-lo cuidadosamente, verifica-se que não há nenhuma inverdade no texto do autor. No entanto, algumas reações foram enérgicas, entre elas a de Ziraldo: no momento mesmo da conclusão da fala proferida por Ruffato, em meio aos aplausos do público, Ziraldo gesticulava e condenava o que acabara de ouvir. Desse modo, o discurso converteu-se em polêmica em dois sentidos. O primeiro deles é o sentido corrente daquilo que é passível de discussão e questionamento, aquilo que pode ser polemizado. $\mathrm{O}$ segundo é o de polêmica como um tipo ou modelo de debate cultural cujas raízes reportam a certas práticas hoje pouco usuais da crítica literária. Conforme observa Jobim,

o gênero "polêmica" não é novidade, pois a polêmica está associada à crítica literária desde o século XIX. Também estamos cientes de que muitas vezes o desejo de "destruir reputações" em alguns casos desandou em ofensas pessoais entre os envolvidos. Ou seja, a "polêmica" também tem como tradição que os polemistas evoluam da troca de argumentos para a troca de insultos (Jobim, 2012, p. 151). 
A circulação do discurso de Ruffato converteu-o também em polêmica nesse sentido específico. É possível entender (mas não justificar) os usos de qualificativos pejorativos, e até mesmo insultos, dirigidos diretamente a Luiz Ruffato, e não às ideias defendidas por ele na abertura do evento, quando se nota o desdobramento da polêmica como pretenso debate. Apesar de que o modo violento como tal debate se desenvolveu acabou restringindo muito de seu significado politizado à oposição entre grupos político-partidários definidos que, naquele momento, já alavancavam suas bandeiras rumo às eleições presidenciais que ocorreriam no ano seguinte no Brasil, isto é, 2014.

É o que podemos observar, por exemplo, em textos como o do sociólogo e jornalista José Maria e Silva (2013), intitulado "Luiz Ruffato confunde arte com panfleto e envergonha o Brasil em Frankfurt", originalmente publicado no jornal Opção, ou "O discurso de Luiz Ruffato em Frankfurt", de Rodrigo Constantino (2013), publicado no site da revista Veja.

Desconsiderando todos os protocolos institucionais dos debates acadêmicos atuais, ambos os autores são, de fato, descorteses nesses textos. José Maria e Silva chega a se referir a Ruffato com expressões como "burrice" e "analfabetismo funcional", além de criticar o autor por aquilo que chama pejorativamente de "lamentáveis momentos 'USP' de seu discurso". Em sentido rigoroso, nenhum dos dois textos é digno de uma discussão detida, porque se pautam nas visões de mundo dos seus autores - evidentemente neoliberais -, que recorrem ao discurso de Ruffato para defender pontos de vista pessoais, que não precisavam do discurso do escritor como via de diálogo e que, no fundo, não o consideram séria nem respeitosamente. Ambos recorrem à estratégia de denegrir e ridicularizar a pessoa e o discurso de Ruffato como via para tentar descredenciar as ideias postas em pauta pelo escritor.

Desse modo, ao negarem o discurso de Ruffato, críticas como a de Constantino ou a de José Maria e Silva confirmam o argumento do escritor em seu discurso, segundo o qual a estrutura cindida do tecido social brasileiro cria barreiras que funcionam como fronteiras em sentido profundo e, "como não enxergamos o outro, o outro não nos vê" (Ruffato, 2013, p. 2). Em termos de construção retórica, os dois jornalistas ignoram integralmente o texto de Ruffato em nome da defesa de seus próprios paradigmas epistêmicos. A violência do tom e os termos pejorativos e ofensivos presentes nas críticas acabam revelando a violência de uma 
tradição discursiva que, em nome do progresso, silencia o outro, nega-lhe a existência ou, inclusive, procura ridicularizá-lo como via para tentar invalidar os saberes por ele postos em circulação.

Esse comportamento desvela certos pontos de tensão entre aquilo que é legitimado como conhecimento (assentado numa tradição epistêmica que se confere o direito de categorizar, hierarquizar ou invalidar aquilo que não se enquadra em seu paradigma) e o que é relegado à condição de "testemunho" ou, no máximo, de "saber". A questão-chave, aqui, é que tal tradição discursiva aceita o outro e sua crítica desde que eles se enquadrem no lugar do menor, reconhecendo, desse modo, sua condição excepcional. Aliás, o choque provocado nesses setores pelo discurso de Ruffato associa-se também ao fato de o escritor ter implodido parcialmente sua condição marginal naquele contexto, justamente porque, como orador na abertura da FLF, ele provisoriamente invalidava, ali, a distinção entre centros e periferias na linguagem, valendo-se desse contexto de exceção para mostrar, paradoxalmente, que as fronteiras e as margens não são, contemporaneamente, apenas um traço retórico no tecido social brasileiro.

A esse respeito, a própria escolha de Ruffato como autor do discurso de abertura da FLF em 2013, em vez de apontar para alguma mudança profunda no funcionamento das instituições sociais e literárias, parece confirmar sua rigidez. De modo semelhante, por exemplo, ao chileno Pedro Lemebel, que foi o primeiro escritor declaradamente gay a receber uma bolsa Guggenheim para escrever um livro, a escolha de Ruffato confirma a exceção que ele ainda representa ou constitui, apesar de hoje não se confundir mais com os filhos de pipoqueiros semianalfabetos e lavadeiras analfabetas. Como Santiago Vega (Washington Cucurto), na Argentina, que teve de aprender a língua do outro para introduzir-se no sistema literário argentino e poder proceder a uma crítica dos processos institucionais da literatura a partir de dentro desse mesmo sistema, Ruffato teve de se tornar o "escritor Luiz Ruffato", lido e reconhecido internacionalmente, para poder chegar ao discurso de abertura da FLF.

A repercussão negativa de seu discurso entre amplos setores das classes médias mostra que, longe de ter se tornado algo comumente aceito, sua condição à deriva entre o campo intelectual e a periferia ainda provoca recusas e revela uma espécie de estratificação da cultura letrada, marcada pelo preconceito e o racismo. Conforme o próprio escritor relata em entrevista recente a Thomaz, "depois de meu discurso em Frankfurt, 
teve escritor brasileiro dizendo em rede social: 'É isso que dá deixar o filho de um pipoqueiro e de uma lavadeira falar em nome do Brasil'" (Thomaz, 2015, p. 2).

$\mathrm{O}$ "choque de recepção" provocado nos setores mais reacionários da sociedade brasileira talvez se deva ao fato de Ruffato ter se colocado na contramão de uma espécie de tendência recente, pautada no "politicamente correto", segundo a qual os escritores evitam a dissidência declarada como forma de não se envolverem em conflitos que coloquem em risco sua reputação. Como observou Daniel Mandur Thomaz,

Luiz Ruffato é uma espécie em extinção na fauna literária brasileira: um autor que se posiciona como intelectual público, que não se esconde por detrás de preciosismos estéticos e fala sobre o Brasil, e seus complexos problemas, sem medo de se comprometer, sem beijamãos ou rapapés (Thomaz, 2015, p. 1).

Acrescentemos, ainda, que Ruffato também não se enquadra no perfil do escritor brasileiro contemporâneo que, como registra Dalcastagnè (2012), em geral trata de temas e contextos urbanos associados às classes médias. Ruffato é um escritor que põe no centro de suas preocupações o homem comum e trabalhador - e nisso também pode ser comparado a Washington Cucurto -, aspecto que caracteriza sua escrita como sendo claramente politizada, conforme ele mesmo declara na entrevista a Daniel Thomaz: "Toda minha escrita se constituiu como parte de uma decisão política. Na literatura de ambientação urbana no Brasil, não há representações da classe média baixa, do trabalhador. E isso não só na literatura" (Thomaz, 2015, p. 2).

Retomando a expressão que dá título a um ensaio de Eric Hobsbawm (1998), Ruffato faz ficção "de baixo para cima", no campo da representação literária. Sua perspectiva dissidente confirma-se se nos lembrarmos do que diz Regina Dalcastagnè sobre a literatura brasileira contemporânea, ao observar, a partir de uma pesquisa realizada com romances publicados entre 1990 e 2004, que chama a atenção

o fato de que mesmo entre os homens, a maioria das personagens não se insere no espaço profissional. Lembrando ainda que a grande maioria das personagens masculinas é madura, portanto, plenamente incorporadas ao mercado de trabalho, a incongruência fica ainda mais evidente. É como se o trabalho - com todo o seu universo formado pelos colegas e os chefes, as pressões, as intrigas, o jogo de poder, as fofocas no botequim ao final do dia - não fosse um tema digno para a literatura (Dalcastagnè, 2012, p. 169). 
É como se o campo contemporâneo brasileiro de representação literária ainda portasse certas reminiscências de um passado marcado por estruturas sociais rígidas, em que a mobilidade social não está prevista, e o trabalho ainda é visto como sendo um universo menor, degradado, potencialmente associado ao âmbito da servidão e da escravidão. Tais reminiscências apontam, por sua vez, para a sobreposição de temporalidades na constituição do tecido social, no presente, pois estão em jogo, segundo essa perspectiva, uma temporalidade pré-moderna (ancorada no feudalismo, que se pauta na servidão e na posse de grandes propriedades); uma temporalidade moderna precária, em que o universo do trabalho e a racionalização da vida são necessários, mas ainda são vistos como marginais; e uma temporalidade plasmada pelas ações da indústria cultural recente e o capitalismo tardio, em que o econômico interfere em todas as esferas do tecido social.

Esse último traço do discurso de Ruffato põe em evidência o interesse contemporâneo que as próprias figuras de autor e de escritor despertam sobre o público em geral, por vezes, inclusive em detrimento de sua obra. Convertida em espetáculo midiático, nos últimos anos, a figura dos escritores passou a fazer parte de um fluxo de imagens - e o fluxo é emblemático do processo de serialização e objetificação operado no meio de produção capitalista -, que circula nos mais diversos meios de comunicação. Justamente por estarem convertidas em fluxo, normalmente não afetam o receptor, que, no entanto, interessa-se por tudo o que acontece com o escritor - biografias, momentos íntimos, flagras obtidos por paparazzi, escândalos etc.

O impacto provocado com o discurso de abertura na FLF deveu-se, nesse sentido, ao fato de Ruffato ter operado uma interrupção momentânea desse fluxo textual. Por meio da ruptura, desvelou para o público a mitificação da própria figura do autor, bem como da literatura convertida em mercadoria no cenário contemporâneo, cuja consequência é a assimilação de seus desdobramentos pelo capital, num processo que, por vezes, acaba desviando a atenção do público para aquilo que pode ser comercializável, em detrimento das ideias que são colocadas em circulação e que, por esse procedimento, acabam silenciadas e parcialmente esvaziadas.

Dispondo de um momento em que as câmeras e os olhares estavam voltados para si, em vez de seguir sua passagem pela "esteira semiótica" do cenário de Frankfurt sem lhe perturbar o ritmo, Ruffato, fez com que a 
esteira se detivesse por alguns instantes, interrompendo tal fluxo com ação de novos e diferentes fluxos práticos e discursivos. Nessa pausa da máquina de produção de signos, a figura tantas vezes objetificada do escritor reavivou-se, como num procedimento de montagem ideológica, e a mise-en-scène de Ruffato no evento pôs em tensão dois modos (não propriamente separados) de tratar o literário contemporaneamente: o comercial e o crítico. Enquanto peça que fazia parte de um protocolo da programação da FLF, Ruffato integrava a esfera comercial posta para a apreciação do público, convertendo-se, parcialmente, em objeto exposto numa espécie de vitrine ou reality show de escritores - não se pode esquecer que havia ali uma comitiva formada por cerca de 70 escritores brasileiros convidados.

De repente, entretanto, o "escritor-autômato" aparentemente coisificado pelo sistema econômico, ao ter se transformado em trabalhador ou "operário das letras", revelou-se um indivíduo em tensão com o mundo, cuja constituição não homogênea tornava sua aparição na feira um acontecimento problemático. Isso, pois passar inadvertido contrariaria sua própria trajetória pessoal e intelectual, uma vez que ele mesmo constituíase num indivíduo que tradicionalmente não teria um lugar para si ali.

Por sua vez, sua condição de indivíduo constitutivamente problemático supera, nesse contexto enunciativo, a concepção moderna de indivíduo problemático, na medida em que, sendo oriundo das margens da periferia do capitalismo, apenas muito entre aspas Ruffato é um escritor semelhante ao indivíduo problemático teorizado por Lukács (2000; 2009) - que é, ao mesmo tempo, o último dos burgueses e o último inimigo dos burgueses. Sua condição singular é, contudo, radicalmente problemática, num nível tal que mesmo a literatura de ficção dos séculos anteriores poucas vezes alcançou, porque reconhece potência crítica e, portanto, individualidade a alguém que, segundo os parâmetros epistêmicos e sociais modernos, sequer figuraria como sendo um indivíduo.

Quando Ruffato dispara sua crítica à sociedade brasileira na FLF, o que ele faz é colocar em primeiro plano uma imagem do Brasil que ali na vitrine de produtos de exportação que a FLF também é - muitos não queriam ver, por considerar que se tratava do que não deve ser "vendido" como sendo o Brasil. Em termos midiáticos, talvez sua mise-enscène possa ser comparada ao defloramento de Márcia, ainda nos capítulos iniciais de O dono do mundo (1991), de Gilberto Braga. Acostumados aos aparecimentos protocolares das classes médias em 
eventos da natureza da FLF, os setores médios que reagiram violentamente ao discurso de Ruffato viram-se, de repente, deslocados da condição de meros espectadores para a de alvo da crítica do autor, em razão da (tradicional e histórica) alienação ou conivência desses grupos.

O escritor fora hábil o suficiente para seduzir o público para si e, no momento em que o público (ou parte dele) estava ali ávido pelo discurso de abertura, rompeu as normas do gênero (protocolar). O público que esbravejou contra o discurso de Ruffato imediatamente após sua leitura ou nas redes sociais é semelhante ao público que, se se tratasse de uma exibição televisiva, teria desligado a TV ou mudado de canal para não ver-se criticado - de modo semelhante ao público que desligou a TV imediatamente após a cena do defloramento de Márcia por Bruno Barreto, na telenovela de Gilberto Braga, ao reconhecer-se na personagem da "virgem que se deixara enganar".

Na FLF, porém, não era o médico "bom moço" que traía o público cativo, mas, sim, o "filho do pipoqueiro e da lavadeira" que, sem nunca ter criado para si a imagem de "bom moço", tinha sido posto no lugar a que até então apenas os bons moços tinham podido chegar. Na verdade, não traiu ninguém, apenas não correspondeu às expectativas de um público acostumado a ver-se representado na mídia sob uma aparência melhorada de si mesmo.

Acostumado ao escritor que, por vezes, aceita ser parte do fluxo econômico, esse setor do público esqueceu-se de que "Luiz Ruffato é uma anomalia. Filho de uma lavadeira analfabeta com um pipoqueiro discursar na maior feira literária do mundo? Jamais se viu. Estatisticamente, Ruffato nem deveria existir. Mas acontece que ele existe" (Porto, 2013, p. 1). Por um lado, seu discurso aponta para aquilo que se tem chamado de virada etnográfica no campo da ficção. Por outro lado, a expectativa de certos setores por um discurso que expressasse orgulho nacional frustrou-se diante de uma espécie de "orgulho nacional às avessas", no qual a própria ideia de nação era posta em xeque, quando Ruffato dava a ver as fraturas estruturais do tecido social brasileiro e a falência dos seus projetos de desenvolvimento. Conforme observou José Miguel Wisnik, "perturbar corajosamente o funcionamento da velha retórica mascaradora, neste momento brasileiro, foi, aliás, o melhor mérito do gesto de Ruffato" (Wisnik, 2013, p. 2).

Caberia, então, perguntar como a textualidade do discurso de Ruffato opera tais deslizamentos de sentido e, inclusive, como o 
discurso de abertura da FLF figura em relação à sua própria mise-enscène autoral. Parte significativa das críticas ao discurso de Ruffato, ainda que se trate de críticas muito diversas entre si, orientaram-se no sentido de que o escritor estaria repetindo clichês já superados sobre o Brasil. Mas rotular como sendo "clichês" os problemas elencados por Ruffato na FLF não faz com que tais problemas deixem de existir e, além disso, sugere que há imagens adequadas e imagens inadequadas do país a serem postas em circulação, o que, no entanto, é controverso. Como escreveu Alexandre Vidal Porto,

Há quem considere que a realidade apresentada por Ruffato reforça um clichê indesejável e persistente do Brasil. Mas seu discurso nada tem de inverídico. Descreve problemas reais do Brasil. O que para muita gente é clichê desagradável para outros é realidade cotidiana. Se algum deles for escritor, provavelmente escreverá sobre isso, e, se chegar a Frankfurt, e discursar, sobre isso falará (Porto, 2013, p. 2).

Nota-se, pois, que o debate do discurso de Ruffato na FLF exige que se interrogue sobre a própria textualidade que se conforma naquele contexto específico. O que é o discurso de Ruffato na abertura da FLF enquanto texto? Como deve ser lido? Que princípios de leitura ele requer? Naturalmente, não se trata de um texto de ficção em sentido corrente, porém, por outro lado, não se separa da produção literária do autor.

E é essa configuração autoral de mil pontas que torna espesso o discurso de abertura da FLF. O acontecimento ao qual sua enunciação está vinculada situa-o, simultaneamente, no âmbito do manifesto e do literário. Atualmente, o manifesto enquanto gênero não constitui uma tendência no campo da agitação literária e cultural, mas foi corrente, por exemplo, no contexto das vanguardas do início do século XX. Como observa Noé Jitrik (1995), normalmente se leem os manifestos por suas ideias, e a produção poética e ficcional por sua configuração literária, mas é pertinente questionar que tipo de pacto de leitura é esse que parece desconsiderar o processo que coloca em cena o debate, por meio do procedimento de certo modo performático, inerente ao próprio manifesto enquanto estrutura textual. Talvez haja continuidades e rupturas no movimento de constituição da textualidade do discurso de Ruffato, o qual, nesse sentido, porta traços de um manifesto, o que explica sua estrutura algo satírica e a expectativa do autor, ao final, de que o processo de conscientização possa provocar mudanças nesse mesmo tecido social que ele critica. 
Desse modo, a utopia de que fala Ruffato ao final do discurso não se confunde com as utopias de esquerda de décadas anteriores, hoje problematizadas pela descrença em quaisquer ideias orientadas por ações de totalização e de síntese. A utopia em questão configura-se como um processo de linguagem capaz de interromper fluxos semióticos em curso e, por isso, potencialmente capaz de agir no tecido social, pois

a modernidade [...] pode ser definida por este fato novo: nela se concebem utopias de linguagem. [...] "Mudar a língua", expressão mallarmeana, é concomitante com "Mudar o mundo", expressão marxiana: existe uma escuta política de Mallarmé, daqueles que o seguiram e o seguem ainda (Barthes, 1977, p. 21-22).

A literatura como compromisso, ideia com a qual Ruffato abre seu discurso, legitima-se, desse modo, na medida em que é compromisso com uma linguagem, com sua mise-en-scène de escritor, com o material de que dispõe o escritor para agir no mundo: a língua - ainda que se trate de uma língua secundária no campo das relações epistêmicas contemporâneas, como o português. Não se trata, portanto, de definir o gesto político pelo que nele se diz político, mas, sim, pelo que se configura como político na linguagem e, fundamentalmente, na enunciação que a coloca em funcionamento num contexto dado. A oposição entre o gesto teatral ou performático do escritor que abre as atividades da FLF com seu discurso polêmico e o caminho político é uma oposição falsa, porque ambos os recursos são envolvidos no processo de desvelar uma série de fraturas da "ideia de Brasil".

Visto nos deslizamentos que opera entre o manifesto, a intervenção artística e a escrita ficcional-etnográfica, o discurso de Ruffato põe em discussão um conjunto de aspectos que as vanguardas das primeiras décadas do século $\mathrm{XX}$ puseram em cena, porém não resolveram (Sklodowska, 1991): a abertura do discurso artístico-literário às linguagens das periferias, a língua coloquial e vulgar, a problemática da nacionalidade, as formas e manifestações artísticas que mal figuram no centro de reconhecimento legitimado no sistema cultural. Mas Ruffato como Cucurto, na literatura argentina contemporânea - também não chega a solucionar essa tensão. Sua contribuição está em pôr em dúvida certos aspectos de valor, de classe e econômicos que continuam firmes no processo de categorização e legitimação do conhecimento no/do Brasil atual. 


\section{As perspectivas de leitura na recepção imediata}

A profusão de opiniões, postagens e pequenos textos sobre o discurso de Ruffato na FLF imediatamente após sua leitura em Frankfurt torna difícil uma síntese das tendências da recepção imediata que sua fala obteve. Mas, do conjunto de leituras dos textos que circularam em $b \log s$, redes sociais, jornais e revistas nos dias seguintes à abertura da feira, é possível divisar ao menos três vertentes de leitura: a) uma, segundo a qual Ruffato envergonhou o Brasil; b) outra, que entende que Ruffato mostrou o Brasil ao mundo; e c) uma terceira, que identifica as porosidades do discurso de Ruffato e defende que ele não se circunscreve, exclusivamente, em " $a$ " ou " $b$ ".

a) A primeira vertente de leitura considera que um discurso como o de abertura da FLF em 2013 cumpre uma função: a de criar uma imagem simpática do Brasil para o mundo. Pode-se dizer que essa perspectiva defende a publicidade de um "Brazil" tipo exportação, isto é, produto de primeira qualidade, sem fissuras, falhas nem irregularidades, dotado de uma espécie de certificado de excelência que o discurso em questão deveria atestar. No contexto de 2013, essa imagem também estava associada ao momento pré-Copa do Mundo da Fifa, que se realizaria no Brasil em 2014, e ao interesse em atrair um significativo número de turistas e consumidores para o país. Não é coincidência que essa é a imagem que Rodrigo Constantino ou José Maria e Silva queixam-se de não aparecer no discurso de Ruffato, acusando-o de ter "envergonhado" o país ao "desfigurar" suas mazelas.

O Brasil em questão é branco, tem um sotaque típico do eixo centrosul do país e chega a confundir-se com certos padrões étnicos e culturais europeus ou norte-americanos situados nos estrados dominantes do tecido social. Não é mera coincidência que, quando os organizadores da Copa do Mundo sugeriram os nomes de Lázaro Ramos e Camila Pitanga como mestres de cerimônia para a abertura do evento, a Fifa os recusou, e eles foram substituídos por Rodrigo Hilbert e Fernanda Lima - o contraste é autoexplicativo. Essa vertente de leitura apostava numa imagem do Brasil como produto assimilado ao gosto eurocêntrico, a ser vendido. Para os adeptos dessa perspectiva, Ruffato "falou mal do Brasil" em seu discurso na FLF.

É preciso observar, contudo, que não é apenas nas críticas diretamente alinhadas a uma perspectiva neoliberal que essa proposta 
de leitura manifesta-se, mas também em críticas oriundas do próprio campo da literatura. Em postagem intitulada "Ruffato fora de foco", de 13 de outubro de 2013, no Facebook, Eliana Ribeiro Viana dos Santos considera que o discurso foi um equívoco e foi prejudicial, porque teria colaborado para perpetuar uma imagem negativa do país, o que seria decorrente de uma ingenuidade das crenças do escritor, que o teriam levado ao erro. Da postagem, vale a pena recuperar o trecho a seguir, apesar de sua extensão:

O discurso de Ruffato além de não poder produzir nada de bom para o Brasil, reforça, pois, a atitude colonialista dos europeus e americanos a nosso respeito, baixa nosso valor simbólico, nos prejudica, em suma, de maneira concreta. A feira de Frankfurt é, como o nome diz, um mercado. Vendem-se e compram-se livros. O Brasil está aí, sobretudo como vendedor, daí essa enorme delegação que o povo brasileiro está pagando. Como a matéria-prima desse produto é o imaginário, o sonho, vendem-se, aí, nações ou ao menos países. Nesse lugar, o que é preciso é uma estratégia de venda. Porque vender a literatura brasileira é pôr em evidência o povo brasileiro, é valorizar a vida dos brasileiros, sua luta por superar suas dificuldades. [...] Que tal propô-lo agora como a terra da resiliência? O país onde filhos de lavadeiras (ou estimadas agregadas de famílias abastadas, é conforme o biógrafo) podem tornar-se amigos de filhos do patriciado a ponto de fundarem juntos a Academia Brasileira de Letras? Onde o filho de um pipoqueiro pode tornar-se ficcionista e ser escolhido para falar por seus pares na maior feira de livros do mundo? Ruffato parece ignorar que seus livros não são bons pela matéria que narram, mas pela mestria com que são narrados. Que literatura não se faz com bons sentimentos ou boas intenções (primeira aula de Teoria Literária). E também (sobretudo?) que não estamos mais na periferia, o centro se alargou. Estamos agora brincando "na cours des grands". E que o que temos de ter é coragem (Santos, 2013b, p. 1).

Não fica claro o modo como o discurso de Ruffato referendaria o (neo)colonialismo, no trecho em questão, especialmente se não nos esquecermos de que ele foi proferido como provocação dentro de uma feira literária num centro do capitalismo ocidental - Frankfurt. No entanto, esse foi um argumento corrente na recepção crítica do discurso, segundo o qual o autor teria se valido de clichês que corroboram a imagem do Brasil como um país bárbaro.

Paradoxalmente, não se questionou o fato de que a imagem de "bárbaro", em contraposição a de "civilizado" que a Europa representaria, também é uma construção cuja base moderna é europeia. Tal constructo 
ganhou corpo no processo de elaboração de uma ideia de América Latina que, na fase de transição da época colonial para a época da fundação das jovens nações latino-americanas, foi assimilada por uma elite criolla, que se identificou, no plano simbólico, com seus (supostos) antecedentes europeus, pretendendo distanciar-se da imagem de "bárbaros latinoamericanos", porém sem colocar em dúvida a própria categoria de "bárbaro". Ao contrário, o conceito continuou vigente como via de hierarquização dos indivíduos, segundo suas respectivas posições social e geo-histórica, a partir de uma categorização de base racista (Mignolo, 2007) alinhada à estratificação e à rigidez do tecido social.

Mas isso também não altera o fato de que o foco posto nessa perspectiva é a estratégia comercial. Chega-se a sugerir que se encontrem novos "cartões de visita" para o Brasil - "terra da resiliência". Também não se discute se essas imagens possíveis seriam alienadoras ou iluminadoras. Chama a atenção que não se chega a colocar em dúvida a ideia de representação de um Brasil. Aliás, esse é um traço corrente nos textos que operaram sua leitura do discurso de abertura da FLF por essa perspectiva: todos tomam o Brasil como sendo uma unidade, algo que não é preciso sequer recorrer a teorias sociológicas para questionar.

É, no mínimo, inconsistente a hipótese de que a literatura e os escritores brasileiros devam encontrar uma estratégia de venda de imagens do Brasil - porque isso o mercado já se encarrega de fazer -, especialmente se se observar que, ao ser transferido para o mercado, $\mathrm{o}$ Brasil (os sonhos, o país ou a nação, por sinédoque, como quer a autora no fragmento acima) converte-se em objeto e, portanto, destitui-se de qualquer rastro humanizador. Como objeto reproduzível orientado para a venda, ele não seria outra coisa além de um souvenir, ruína alienada de um original inexistente.

Enfim, essa perspectiva não coloca em dúvida os próprios pressupostos que orientam sua argumentação - noções como a de centro e periferia, de arte pura e arte engajada, e a de literariedade -, conceitos úteis como operadores de leitura de um conjunto de textos expressivos de uma ideia de modernidade que, no entanto, são históricos e ideológicos. Isso também mostra os impasses do campo da crítica literária contemporânea, no Brasil e na América Latina, ante o desafio de ler o literário para além da esfera da autonomia, que foi tomada, por vezes, como corolário pela crítica moderna, a qual, institucionalizando-a, passou a ver na autonomia um traço fundador do 
próprio texto literário, elidindo o fato de que há textos que nascem literários, outros que alcançam essa condição, e há, ainda, aqueles aos quais se impõe tal condição por ações exógenas e institucionais inclusive, como lembra Culler (1999).

Pois o desafio que o discurso de Ruffato coloca para os críticos da área de Letras também está no fato de que ele se situa, ao mesmo tempo, dentro e fora do literário, do econômico, do espaço público e do espaço privado. Essa condição em trânsito parece marcar não só sua inespecificidade (Garramuño 2014), mas também um estágio de transformação do próprio campo do literário e da crítica contemporâneos.

b) A segunda vertente da recepção do discurso de Ruffato nos dias imediatamente posteriores ao da sua leitura constitui-se no polo oposto da anterior e, ao não colocar em dúvida os conceitos com os quais opera, também se fragiliza. Por um lado, nessa perspectiva, aceita-se que Ruffato procedeu criticamente mostrando o Brasil ao mundo. Em entrevista à Luisa Frey, em 12 de outubro de 2013, por exemplo, elogiando a capacidade demonstrada pela equipe brasileira de integrarse à dinâmica econômica e cultural da feira, Renato Lessa, presidente da Biblioteca Nacional, diz: "Tenho certeza de que Frankfurt tem agora uma boa noção do que é o país" (Frey, 2013, p. 1).

Por outro lado, cria-se uma imagem estática do Brasil como um país de desigualdades potencialmente agenciáveis pelo mercado. Na mesma matéria de Luisa Frey, Ricardo Reis, do departamento de direitos autorais da Cosac Naify afirma: "Além de ser o convidado de honra, com os eventos mundiais que vão ocorrer envolvendo o Brasil [...], acredito que haja um interesse maior do público em descobrir o país. E esperamos que isso venha a gerar mais negócios" (Frey, 2013, p. 2).

Por sua vez, no plano da representação - que também não costuma ser discutido pelos que se orientaram por tal linha de leitura -, o discurso de Ruffato prima por realçar o estado (de certo modo) primitivo das coisas, das relações sociais e dos indivíduos no tecido social brasileiro atual. Talvez escape a essa via de leitura o fato de que nem mesmo o discurso de Ruffato estava livre de ser agenciado, no contexto maior da FLF, para a promoção comercial, isto é, de ser parcialmente espetacularizado pela mídia, pois isso escapa ao controle de seu emissor.

Se convertida em "mito esclarecido", a crítica de Ruffato às fraturas do tecido social brasileiro acaba perdendo parte de seu potencial humanizador e passa, por sua vez, a servir de sustentáculo para a autopreservação do 
sistema de produção em cuja base estão as desigualdades que Ruffato questiona. Nesse sentido, se posto no campo da indústria cultural - por meio de um rearranjo eufórico do conceito que não porte mais o oxímoro que está em sua base -, tal discurso corre o risco de converter-se, também, em expressão de um poder-violência associado ao capital que, ao que parece, corresponde ao oposto das ideias expressas nele por Ruffato.

No entanto, tal hipótese é relevante por mostrar que, no contexto contemporâneo, nada está fora da esfera do capital. Cada vez mais, a indústria cultural se mostra capaz de agenciar para seus objetivos todos os discursos e produtos simbólicos disponíveis no tecido social, a partir de uma operação de esvaziamento de suas raízes políticas. Jürgen Boos, presidente da FLF, disse, em entrevista à Maria Fernanda Rodrigues, que "O Brasil destruiu a imagem que muitos tinham do país. E isso foi bom. Acho que $90 \%$ dos alemães tinham a imagem de um país colorido, com comidas maravilhosas, música, carnaval, de um lugar onde as pessoas não trabalham porque estão fazendo festa a toda hora" (Rodrigues, 2013, p. 1). Porém, ele diz isso no contexto de comércio de livros que a feira promove, chamando a atenção para outro nicho cuja existência o discurso acabava por mostrar, e que o mercado imediatamente percebeu que era vendável, como anteriormente o representante da Cosac Naify também demonstrara.

c) A terceira vertente de leitura do discurso em seu momento inicial não procura conciliar as duas anteriores, mas mostra-se desconfiada em relação a qualquer defesa estanque tanto da autonomia da literatura quanto da homogeneidade de uma ideia de Brasil. De certo modo, mostrou-se mais lúcida justamente por escapar da dicotomia direita/esquerda que, em níveis variados, ecoa nas vertentes anteriores. Alexandre Vidal Porto, por exemplo, afirmou que "Ruffato traduziu de maneira muito fiel o retrato que sua vida de operário the revelou. Nele, presidentes ainda trabalham como torneiros mecânicos e cientistas nunca aprenderam a ler" (Porto, 2013, p. 3, grifo nosso).

Apesar de não dizer explicitamente, o autor sugere que Ruffato não se pauta nos valores pelos quais foi cobrado por alguns setores especialmente oriundos das classes média e média alta. A sugestão de que Ruffato fala em seu discurso a partir de "sua vida" não consiste numa simples mudança de interpretação que disporia de uma base comum em relação à qual as opiniões podem ser diferentes, mas aponta para a existência de universos diferentes que, postos em relação no contexto do capital, não ocupam o mesmo lugar discursivo nem 
epistêmico. Por essa via, o conhecimento não precisa ser avalizado pela racionalidade ou pela ciência civilizada, mas pode proceder de vivências e aprendizados de outras ordens - a oralidade, o trabalho, a vida prática e ordinária que também é plena de saberes que nem sempre chegam a ser legitimados como conhecimento, isto é, não chegam a respaldar-se numa epistemologia.

Em postagem do dia 13 de outubro de 2013, no Facebook, Lidia Santos fez uma crítica ao discurso de Ruffato, numa perspectiva que é semelhante à de Wisnik (2013). Em ambos os casos, a crítica centra-se no fato de que Ruffato pode ter sido radical ao apontar as mazelas sociais do país sem operar certas mediações que indicariam algumas mudanças nessa trajetória. A autora lembra nomes como Ferréz, Conceição Evaristo, Paulo Lins, entre outros, que constituiriam uma ponte com a própria história de Ruffato, e que poderiam servir para traçar uma trajetória mais de acordo com o que a chegada do autor àquele momento significava para amplos setores de artistas e de indivíduos oriundos das periferias brasileiras. José Miguel Wisnik, por sua vez, afirma:

O que é inteiramente ausente no seu discurso é o fato de que existe uma espessura cultural brasileira, uma acumulação artística de longa data, que de muitos modos responde a essas situações e que se desenvolve com e apesar delas. É com essa espessura cultural que o país ganha corpo, opacidade e resistência, mesmo quando obscura. $\mathrm{O}$ ato solitário de escrever, ao qual ele [Ruffato] se apega ao final, não faz sentido sem isso (Wisnik, 2013, p. 2-3).

Nesse caso, o que se cobra é a mediação por Ruffato entre o presente e a série histórico-literária à qual ele mesmo está vinculado na literatura brasileira. Relativamente vasta, ela vai do alto modernismo de Manuel Bandeira - "João Gostoso", por exemplo - a Graciliano Ramos (Vidas secas), passando por nomes como Clarice Lispector (A hora da estrela) ou outros mais recentes, como Ferréz (Capão pecado) ou Paulo Lins (Cidade de Deus), entre outros que poderiam ser elencados. Realmente, Ruffato não faz essa mediação. E talvez isso se deva à escolha, em seu discurso, de alinhar-se a uma espécie de protesto ético, que se pauta no princípio de que, quando se é da periferia ou se fala a partir da periferia, não é preciso rastrear teorias ou autoridades que avalizem o próprio dizer sobre ou da periferia (Mignolo, 2009). Elidir esses rastros na superfície discursiva corresponde, por parte do Ruffato-enunciador, justamente um ato de fala (Austin, 1962). 
Esse Ruffato-enunciador, como aquele João Gostoso sem nome nem endereço do poema de Bandeira, ou a datilógrafa aparentemente alienada que é protagonista de A hora da estrela, ou o Fabiano de Vidas secas, é em algum nível um "Zé Ninguém", e seu anonimato é uma prova disso. Tal enunciador não se confunde com o Ruffato-escritor, hoje reconhecido internacionalmente, mas é instância posta em circulação na língua-ato em sua leitura do discurso. Sem se preocupar em representar propriamente uma realidade social, esse tímido Ruffato (note-se, por exemplo, a discrição de sua voz na leitura do discurso) é também instância umbilicalmente ligada a esse universo periférico: "Fiz um discurso em homenagem ao meu pai e à minha mãe, que já morreram. Eles eram a parte mais esquecida da sociedade brasileira", diz Ruffato em entrevista a Maria Fernanda Rodrigues, momentos após a leitura do discurso (Rodrigues, 2013, p. 2).

Desse modo, uma vez que essa linha histórica de força e tensão está à disposição dos leitores-receptores críticos brasileiros (algo que não poderia ser estendido, por exemplo, ao contexto do público internacional da FLF, que não necessariamente conhece bem a literatura brasileira anterior), é sintomático que tenham sido relativamente poucas as vozes que a reivindicaram como legítima de uma tendência importante da qual o próprio Ruffato faz parte - entre os nomes aqui citados, apenas Lidia Santos e Wisnik o fazem.

Enquanto manifesto que o discurso em questão também é, Ruffato elide essa ponte como possível provocação. Contudo, se alguns desses nomes que estavam ali (Paulo Lins e Ferréz estavam na FLF, por exemplo) não chegaram a ser amplamente notados como marcas de uma mudança em curso, não haveria, então, certa razão no diagnóstico de Ruffato, de que pouca coisa mudou significativamente no tecido social brasileiro? A chegada, nas últimas décadas, de escritores oriundos das periferias ao sistema literário aponta para alguma mudança na cena literária, porém as trajetórias individuais também mostram que seus respectivos percursos não costumam seguir as mesmas vias dos escritores vindos das classes médias e do contexto de produção cultural legitimado, como o jornalismo ou a academia, por exemplo.

$\mathrm{Na}$ maioria das vezes, eles precisam traçar caminhos alternativos (debates paralelos aos já institucionalizados, antologias próprias, coletivos artístico-literários etc.) para que o sistema literário seja forçado a uma rearticulação de seus valores e de suas bases institucionais: sua inserção 
aponta, também e paradoxalmente, para sua condição de diferença. Sua integração parece reiterar o não pertencimento ou a não normalidade do pertencimento. Considerando-se o excesso típico do tom de manifesto de seu discurso, nisso Ruffato também não se enganava de fato, pois não nega a mudança, em seu discurso, mas chama a atenção para o quão reduzida ela ainda é no campo literário brasileiro.

Quanto a isso, há que se notar que as posições dos agentes sociais, bem como das próprias noções de indivíduo (burguês), escritor (letrado) e autor, mantêm-se praticamente inalteradas, no percurso da modernidade na América Latina até muito recentemente, uma vez que tais posições instalam-se numa dinâmica capaz de estabelecer padrões e classificações, ao mesmo tempo que se encaixam neles. Nesse sentido, a própria noção de outro, por vezes presente no plano da ficção, parece constituir-se numa espécie de "estranho de si mesmo" criado em nome da representação, da verossimilhança ou do realismo.

Isso é o "normal", o corrente e, até mesmo, o esperado nas práticas discursivas que orientam as literaturas na América Latina ao longo de toda a modernidade, de certo modo, e tal naturalização acaba por silenciar aquilo que o autor cala ao se pronunciar. Como consequência, tais práticas sociais e discursivas alimentam a ideia de que certos grupos e categorias individuais ou culturais não fazem parte da história nem do que vale a pena narrar e representar - talvez porque não façam parte, sequer, daquilo que normalmente se entende como indivíduo.

\section{Paradigmas em disputa}

A textualidade da polêmica do discurso de Ruffato em Frankfurt, associada a sua repercussão inicial, aponta para um processo de disputas e crises relevantes para o campo de reflexão sobre a literatura atual em curso também em outras partes do mundo, como se pode ver, por exemplo, nas reflexões de Laddaga (2006) e de Ludmer (2007; 2010), para a qual os críticos também já chamam a atenção no Brasil (Ginzburg, 2012; Santiago, 2012; 2015a; 2015b), destacando a necessidade de novas perspectivas de interpretação e análise de algumas produções artísticas e literárias contemporâneas.

A noção de crise que emerge nesse contexto liga-se à ideia de mudança, reformulação e rearticulação, não necessariamente à de decadência. Isto é, não se trata de uma concepção teleológica do campo cultural e dos 
processos discursivos da literatura, mas, sim, do conjunto de discursos que, ao serem elaborados, vão engendrando imagens contemporâneas da literatura atual e colaboram para a visibilidade da emergência de um paradigma da cultura das artes que já não corresponde plenamente ao paradigma da cultura da arte moderna surgido há mais de dois séculos. Ao mesmo tempo, põe em pauta reivindicações pela coexistência entre novos agentes culturais e outros já legitimados e, ainda, problematiza os vínculos entre literatura e representação - nos moldes em que são tratados tradicionalmente, a partir de um viés mimético-realista -, por meio de uma revisão dos projetos literários nacionais que marcaram a literatura moderna na América Latina. Pode-se designar tal processo como um "desrecalque histórico" (a expressão é de Ginzburg), "uma atribuição de voz a sujeitos tradicionalmente ignorados ou silenciados" (Ginzburg, 2012, p. 200).

Por um lado, a própria configuração da mise-en-scène autoral e da textualidade do discurso de Ruffato na FLF sugere a emergência desse novo paradigma no campo artístico, pois não há chaves claras que indiquem como podemos falar de "propostas de intervenção" como essa, o que torna sua abordagem um desafio. Por outro lado, sua intervenção deixa claro que não cabe nos limites de certo modelo de teoria literária cuja afirmação e predominância ocorreram entre os anos 1940 e meados de 1960, aproximadamente.

Não se trata de uma ação discursiva pautada no isolamento típico do indivíduo burguês mais característico do horizonte crítico da modernidade, que se propõe manter distância do mundo para, paradoxalmente, chegar ao seu âmago na linguagem (autônoma). Ao mesmo tempo, também não se trata de uma ação plenamente coletiva, uma vez que está vinculada ao ato de fala do escritor num momento e lugar determinados, e que não há, nesse contexto enunciativo, uma concepção de coletividade homogênea que Ruffato pudesse representar. O processo discursivo que tem no discurso proferido em Frankfurt um momento emblemático é parte de uma trajetória maior, por vezes difusa, em que estratos sociais, culturais e linguísticos entram em contato por meio do choque e estão associados a "um conjunto de forças voltadas contra a exclusão social, política e econômica" (Ginzburg, 2012, p. 201).

Nos últimos anos têm se desencadeado no Brasil eventos que denunciam, por exemplo, a crise do sistema de segurança pública, bem como a violência e o abuso de poder cometidos por membros ligados às instituições responsáveis pela manutenção do bem-estar social, como a 
polícia - a crise desencadeada em relação às Unidades de Polícia Pacificadora (UPP), no Rio de Janeiro constitui-se numa amostra dessas tensões. Enquanto as ações do poder-violência ainda respondem a um modelo organizacional típico do estado moderno hierárquico e centralizado, movimentos populares e massivos emergem nas redes sociais e provocam repercussões nas próprias ações das instituições jurídicas e políticas - é exemplar a onda de protestos encabeçada pelo mote "Onde está o Amarildo?" ocorrida em 2013.

Outro caso expressivo são as ondas de "manifestações separatistas" opondo o eixo Centro-Sul ao Norte-Nordeste do país, que circularam em redes sociais após a eleição presidencial de 2014, promovidos, de modo geral, por indivíduos de classe média e média alta alinhados ao primeiro desses eixos e que puseram em discussão as profundas fraturas e a violência simbólica, tradicionalmente amenizadas por uma retórica que, em nome do progresso, prega uma imagem do Brasil como sendo uma democracia étnica, mito que acaba por mascarar as desigualdades econômicas que estão na base de tais tensões sociais.

Paradoxalmente, em meio a processos e momentos de iluminação nesse complexo de discursos e eventos sociais, emergem outros que, passada a fase inicial, também se vinculam a novos processos em curso e interferem nas trajetórias uns dos outros - como as marchas contra a corrupção ocorridas no primeiro semestre de 2015, no Brasil, e posteriormente aniquiladas por casos de corrupção envolvendo muitos de seus mentores e organizadores. Trata-se de processos que ocorrem

em sistemas de elementos que realizam ações simples, que podem muito bem ser dirigidas em sua interação [...] por leis simples, mas que, quando se reúnem em campos de atividade e impacto, produzem regularidades que nenhum exame deles separadamente permitiu prever. [...] Onde há outras emergências, com as quais interagem, em comunicações nas quais incrementam sua competência (Laddaga, 2006, p. 287-288).

Desse modo, o discurso de Ruffato na FLF irrompe como um aprendizado dissonante, no qual tanto a figura autoral quanto a figura enunciativa "anônima" às quais a história do escritor se liga desempenham funções diferentes e complementares. Enquanto a primeira viabiliza a concretização de sua intervenção-provocação crítica, a segunda funciona como um avatar que, sem a pretensão de representar uma totalidade abstrata, não impede que outros, no entanto, se reconheçam e reconheçam 
os seus no discurso e na persona enunciativa de Ruffato: “'Ruffato me representa e esse discurso talvez seja a melhor coisa que venha a acontecer nessa feira', disse o escritor Paulo Lins" (Rodrigues, 2013, p. 3), em Frankfurt. Porém, simultaneamente, essa possibilidade de identificação e reconhecimento se choca com movimentos em outras direções: “'Aqui [na FLF] não era o lugar. Ele deu todos os dados da miséria brasileira que encontramos no Google. Se fosse em Doha, tudo bem', comentou [Ziraldo], referindo-se ao Fórum Econômico Mundial. Quando Ruffato terminou e a plateia começou a aplaudir, ele, dedo em riste, disse: 'Não tem que aplaudir!"” (Rodrigues, 2013, p. 3). É, aliás, expressivo que o choque, nesse ponto, também se produza entre gerações (Paulo Lins e Ziraldo), pois o discurso de Ruffato também põe em contato temporalidades e imagens dissonantes do Brasil - passado e presente; pujança e subdesenvolvimento; colônia e neocolônia, periferia e semiperiferia etc.

Tais deslizamentos de sentido - entre o intelectual e o homem simples, entre o especialista e o agitador, entre a objetividade e as memórias pessoais - apontam para a crise de uma perspectiva disciplinar de pensamento, que modernamente tendeu a separar tais esferas. $\mathrm{O}$ evento envolvendo Ruffato em Frankfurt assinala o surgimento de um regime prático das artes contemporâneas, ao mesmo tempo que sugere o quão indissolúveis são as relações entre o indivíduo e o trabalho no contexto atual. Não parece coincidência que, no que se refere ao campo cultural brasileiro, esse processo torne-se emblemático num contexto que se concretizou fora do território nacional, em Frankfurt, numa situação única geográfica e discursivamente, espécie de "laboratório de escrita", para dialogar novamente com Laddaga (2010).

A crise da separação entre individualidade, trabalho, ação política e intelectual torna urgente o reconhecimento dessa porosidade no tratamento de demandas discursivas do presente, como essa trazida à cena pelo escritor na FLF. E o discurso do autor parece atender a essa conjuntura. De certo modo, sua intervenção na FLF inscreve-se num processo mais amplo de busca de perspectivas de renovação, para a qual "a recorrência de alguns recursos de escrita pode ter um significado político crítico e afirmativo" (Ginzburg, 2012, p. 201).

Sua inespecificidade torna-o literário e aliterário, materialidade constituída de uma hibridação que encontra legitimidade na história mais ampla dos discursos de matiz histórico-social, na literatura latinoamericana (desde Las Casas, José Hernández, Euclides da Cunha etc.), 
mas, ao mesmo tempo, não se confunde com os anteriores, por seu contexto particular: a potência do próprio contexto em que o discurso se tornou público, em Frankfurt. Numa sucessão de paradoxos, essa característica o dota de um poder particular para desestruturar tanto a suposta unidade do tecido social brasileiro quanto as balizas da crítica para a abordagem desse evento discursivo, que, de certo modo, funciona como uma dessas instalações artísticas contemporâneas que, aparentemente, não se limitam ao produto final e apontam para as linhas de força que as tornaram possíveis (Garramuño, 2014).

O discurso de Ruffato deu visibilidade a "cadeias de solidariedade" que servem para interrogar a mentalidade crítica, pautando-se num princípio ético: "a convicção da necessidade de pluralizar o poder e problematizar a violência" (Laddaga, 2006, p. 66, tradução nossa). Por essa via, o presente de esferas individuais e culturais que já existiam, mas são, por vezes, silenciadas no tecido social, fabrica-se na linguagem-ato que o discurso materializa, dando-se a ver publicamente, em forma de rede de eventos e discursos. "[E]ste tipo de trabalho nos força a pensar sobre questões e consequências da arte fora dos limites da arte" (Garramuño, 2014, p. 97).

Por um lado, esse efeito é resultado de um conjunto de procedimentos elaborados na linguagem - estéticos, portanto -, mas, por outro, aponta para a crise epistemológica da ideia moderna de autoridade ligada à voz que enuncia ou narra. Tal enunciador, que pode ou não se confundir com o narrador do relato, a depender de cada texto, não dispõe mais da condição "soberana", que se outorga o direito de representar o mundo sem questionar os modos como tal legitimação ocorre - diferenciando-se, portanto, o seu status jurídico daquele que caracteriza a autoridade do narrador típico da literatura moderna, mais evidente no romance de base realista. É também por essa razão que a intervenção de Ruffato em Frankfurt é, em certa medida, performática, visto que, ao instalar-se num lugar discursivo correlativo ao estatuto jurídico que o próprio Ruffato apresenta naquele contexto, sua condição encontra na ficcionalização de suas próprias vivências e imagens biográficas uma estratégia produtiva para criar um lugar enunciativo. Por sua vez, tal lugar é tão real e, simultaneamente, tão ficcional quanto aquilo que, na linguagem, seu discurso cria, por ser, de certo modo, correferente das estruturas sociais em meio às quais se desenvolve, marcadas por simulacros que tornam mais complexa a noção de realidade. 
O discurso de Ruffato na FLF dá visibilidade - ainda que de modo indireto - a projetos de coexistência ética, política e epistêmica, não necessariamente pacíficas, mas de "conflito e reclamação ao direito de reexistência [...] em todos os níveis do pensar e do viver" (Mignolo, 2009, p. 256, tradução nossa). Esse tipo de reivindicação permite entender o modo como o escritor conclui seu discurso, apostando na busca da felicidade. No plano da linguagem, trata-se de uma busca permanente, em que o contato com os signos da desigualdade, da diferença e do não pertencimento também potencializa o gozo da experiência na linguagem, em sua capacidade de fazer os saberes girarem, de não fixá-los, possibilidade que se apresenta tanto para o escritor quanto para o leitor comum e, nesse sentido, funda-se num princípio de base democrática.

Eis outro paradoxo, já que o discurso em questão projetou-se via mass media e, desse modo, instalou-se numa dinâmica em que a liberação (da linguagem) e a contenção (dos media) são responsáveis pelo espessamento da linguagem-ato que faz do discurso de Ruffato em Frankfurt uma crítica do próprio campo literário contemporâneo no Brasil, seja no âmbito da crítica, por vezes "incapaz de se repensar e de estabelecer ligações mais consequentes com o próprio tempo" (Sussekind, 2010, p. 4), seja no âmbito da criação literária, por vezes marcada pela "falta de crítica, falta de autocrítica e de ambição" (Dalcastagnè, 2012, p. 194).

A contrapelo, o discurso de Ruffato na FLF constitui-se numa escrita de risco - de não aceitação, de agressão, de despertar ódio, de erros, de excessos etc.-, mas, justamente por tal configuração, mostra-se coerente com o universo descontínuo do qual trata e no qual se insere, uma rede de relações e fluxos que põe em colisão indivíduos e também outros fluxos, tornando-se, desse modo, discursivamente produtiva de novas fraturas e novos processos simbólicos no tecido social.

No caso particular do campo literário brasileiro, o discurso de Ruffato na FLF parece apontar, ainda, para um corte epistemológico no modo de ler, pensar e, inclusive, investigar a literatura neste início de século XXI, que começa a desenhar-se em virtude das fraturas que o discurso da formação apresenta hoje, em meio à crise dos projetos e discursos ordenadores de uma ideia de nação e nacionalidade pretensamente moderna e modernizadora, que falhou ao não alcançar a todos, justamente por sua rigidez. Cada vez mais, torna-se necessário um olhar para o campo literário brasileiro em suas relações com os processos de inserção cultural, tanto interna quanto externamente no cenário atual, marcado pela 
reconfiguração (e também pelas disputas) no âmbito dos próprios discursos teóricos e críticos sobre a literatura, após um período em que a teoria da literatura teve seu auge, aproximadamente entre os anos 1940 e 1960/70.

Ruffato é emblemático desse processo de transformação que requer um novo olhar da crítica para o campo literário - mas não é o único -, pois ao mesmo tempo se vincula ao universo das margens de nosso sistema sociocultural e literário e ao movimento de expansão para além de suas fronteiras, como, aliás, a FLF de 2013 mostra, seja no campo da criação literária ou, inevitavelmente, também, no âmbito do mercado. "Novas condições materiais definem o novo milênio brasileiro. Elas passam a exigir outro feixe amplo e crítico de discursos afins e complementares, que constituirão novo paradigma - o da 'inserção' do Brasil no conjunto das nações" (Santiago, 2015b, p. 6).

O discurso de Ruffato em Frankfurt não só colocou em cena a diversidade e as tensões do campo literário no Brasil, mas também, de modo difuso e nem sempre muito evidente à primeira vista, pôs na agenda da literatura brasileira os processos e as transformações em curso no âmbito da criação, da crítica e das metodologias de leitura contemporâneas do literário. "Não é tão fácil ler uma experiência de escrita. Isso requer uma experiência de leitura, o que é algo muito mais raro" (Deleuze, 2005, p. 10, tradução nossa), e um dos méritos de Ruffato parece ter sido, pois, o de chamar a atenção dos críticos brasileiros para a necessidade de se empreenderem também novas experiências no campo do exercício analítico, novos caminhos de especulação.

De modo semelhante, em certa medida, à distância estética entre o leitor/espectador e o narrador, que era fixa na narrativa tradicional, mas agora varia, "o leitor é ora deixado do lado de fora, ora guiado pelo comentário até o palco, os bastidores e a casa de máquinas" (Adorno, 2003, p. 61). A polêmica levantada pelo discurso de Ruffato na FLF mostra que o atual desafio da crítica é aceitar-se como parte desse universo (que, afinal, é o da leitura), que também é, simultaneamente, objetivo e ficcional, de aproximação e distanciamento, movimento à deriva sob o risco de configurar-se numa forma inacabada. 


\section{Referências}

ADORNO, Theodor (2003). Posição do narrador no romance contemporâneo. In: ADORNO, Theodor. Notas de literatura I. Tradução de Jorge M. B. de Almeida. São Paulo: Duas Cidades, p. 55-63.

AUSTIN, John Langshaw (1962). How to do things with words. Cambridge: Harvard University Press.

BARTHES, Roland [1977]. Aula. Tradução de Leyla Perrone-Moisés. 14. ed. São Paulo: Cultrix.

CONSTANTINO, Rodrigo (2013). O discurso de Ruffato em Frankfurt. Veja.com, São Paulo, p. 1-2, 9 out. Disponível em: <http://goo.gl/0b3K18>. Acesso em: 12 out. 2013.

CULLER, Jonathan (1999). Teoria literária: uma introdução. Tradução de Sandra Guardini T. Vasconcelos. São Paulo: Beca produções culturais.

DALCASTAGNÈ, Regina (2012). Literatura brasileira contemporânea: um território contestado. Vinhedo: Horizonte; Rio de Janeiro: Eduerj.

DELEUZE, Gilles (2005). Derrames entre el capitalismo y la esquizofrenia. Buenos Aires: Cactus.

FREY, Luisa (2013). Feira do Livro de Frankfurt mudou a imagem do Brasil no exterior, dizem organizadores. Cultura. DW, p. 1-3, 12 out. Disponível em: <http://goo.gl/1233pU>. Acesso em: 13 out. 2013.

GARRAMUÑO, Florencia (2014). Frutos estranhos: sobre a inespecificidade na estética contemporânea. Tradução de Carlos Nougué. Rio de Janeiro: Rocco.

GINZBURG, Jaime (2012). O narrador na literatura brasileira contemporânea. Tintas - Quaderni di letterature iberiche e iberoamericane, Milano, n. 2, p. 199-221.

HOBSBAWM, Eric (1998). A história de baixo para cima. In: HOBSBAWM, Eric. Sobre história. Tradução de Cid Knipel Moreira. São Paulo: Companhia das Letras, p. 216-231.

JAMESON, Fredric (1991). Ensayos sobre el posmodernismo. Tradução de Esther Pérez, Christian Ferrer y Sonia Mazzco. Buenos Aires: Imago Mundi.

JITRIK, Noé (1995). Las dos tentaciones de la vanguardia. In: PIZARRO, A. (Org.). América Latina - Palavra, literatura e cultura: vanguarda e modernidade. São Paulo: Memorial; Campinas: Editora da Unicamp, p. 57-74.

JOBIM, José Luís (2012). Crítica literária: questões e perspectivas. Itinerários, Araraquara, n. 35, p. 145-157. 
LADDAGA, Reinaldo (2006). Estética de la emergencia: la formación de otra cultura de las artes. Buenos Aires: Adriana Hidalgo.

LADDAGA, Reinaldo (2010). Estética de laboratorio: estrategias de las artes del presente. Buenos Aires: Adriana Hidalgo.

LUDMER, Josefina (2007). Literaturas posautónomas. Ciberletras - Revista de crítica literaria y de cultura, Cagua, n. 17. Disponível em: <http:/ /goo.gl/VXIpZe>. Acesso em: 10 ago. 2010.

LUDMER, Josefina (2010). Notas para Literaturas posautónomas III. On-line. Disponível em: <http://goo.gl/Yp1SUo>. Acesso em: 20 de ago. 2014.

LUKÁCS, George (2009). O romance como epopeia burguesa. In: LUKÁCS, George. Arte e sociedade: escritos estéticos (1932-1967). Tradução de Carlos Nelson Coutinho e José Paulo Netto. Rio de Janeiro: UFRJ, p. 193-243.

LUKÁCS, George (2000). Teoria do romance. Tradução de José Marcos Mariani de Macedo. São Paulo: Duas Cidades; Editora 34.

MIGNOLO, Walter (2009). La idea de América Latina (la derecha, la izquierda y la opción decolonial). Crítica y emancipación, Buenos Aires, n. 2, p. 251-276.

MIGNOLO, Walter (2007). La idea de América Latina: la herida colonial y la opción decolonial. Tradução de Silvia Jawerbaum y Julieta barba. Barcelona: Gedisa.

PÊCHEUX, Michel (1990). O discurso: estrutura ou acontecimento. Tradução de Eni Pulcinelli Orlandi: Campinas: Pontes.

PORTO, Alexandre Vidal (2013). O país dos pipoqueiros. Folha de S. Paulo, São Paulo, p.1-3, 12 out. Disponível em: <http://goo.gl/lnG3JL>. Acesso em: 12 out. 2013.

RODRIGUES, Maria Fernanda (2013). "Vocês não escolheram Ruffato para fazer o discurso por acaso", diz presidente da Feira de Frankfurt. Estadão.com.br/blogs, São Paulo, Cultura, p. 1-4, 12 out. Disponível em: <http://goo.gl/5I5tpD>. Acesso em: 12 out. 2013.

RUFFATO, Luiz (2013). Leia a íntegra do discurso de Luiz Ruffato na abertura da Feira do Livro de Frankfurt. Folha de S. Paulo, São Paulo, Cultura, p. 1-3, 8 out. Disponível em: <http://goo.gl/JCEkYO>. Acesso em: 12 out. 2013.

SANTIAGO, Silviano (2015a). A literatura brasileira precisa superar o paradigma da formação e entrar no da inserção. Belo Horizonte, p. 1-5, 10 mar. Disponível em: <https://www.ufmg.br/online/arquivos/037483.shtml>. Acesso em: 11 mar. 2015.

SANTIAGO, Silviano (2015b). Anatomia da formação: a literatura brasileira à luz do pós-colonialismo. Folha de S. Paulo, São Paulo, p. 1-6, 7 maio. Disponível em: <http:/ /goo.gl/gG55pQ>. Acesso em: 7 maio 2015. 
SANTIAGO, Silviano (2012). Formação e inserção. Estadão, Cultura,p. 1-2, 26 maio 2012. Disponível em: <http:/ / goo.gl/bDF24s>. Acesso em: 10 maio 2015.

SANTOS, Eliana Ribeiro Viana dos (2013b). Ruffato fora de foco. 12 out. 2013 b. Postagem no Facebook. Disponível em: <https://goo.gl/lESWqV>. Acesso em: 12 out. 2013.

SANTOS, Lidia (2013a). Escrevi o que vai abaixo como resposta a um post de minha amiga Iris Kantor, citando à crítica de Zé Miguel Wisnik (ainda) ao discurso de Rufatto. 12 out. Postagem no Facebook. Disponível em: <https://goo.gl/Qa8eSh>. Acesso em: 12 out. 2013.

SILVA, José Maria e (2013). Luiz Ruffato confunde arte com panfleto e envergonha o Brasil em Frankfurt. Opção, Goiânia, p. 1-5, 13 out. Disponível em: <http://goo.gl/EoR6OW>. Acesso em: 14 out. 2013.

SKLODOWSKA, Elzbieta (1991). La parodia en la nueva novela hispanoamericana. (1960-1985). Amsterdam/Philadelphia: John Benjamins Publishing Co.

SUSSEKIND, Flora (2010). A crítica como papel de bala. O Globo, Rio de Janeiro, p. 1-4, 24 abr. Disponível em: <http://goo.gl/N8mEyC>. Acesso em: 10 maio 2015.

THOMAZ, Daniel Mandur (2015). Luiz Ruffato: literatura é compromisso. Cultura, Carta maior, São Paulo, p. 1-3, 15 mar. Disponível em: <http://goo.gl/VMqar8>. Acesso em: 1 abr. 2015.

WISNIK, José Miguel (2013). Zé Miguel Wisnik fala sobre o discurso de Luiz Ruffato na cerimônia em Frankfurt. Blog do Guto, Rio de Janeiro, p. 1-4, 13 out. Disponível em: <http://www.circusproducoes.com.br/blog/?p=3931>. Acesso em: 15 out. 2013.

Recebido em setembro de 2015.

Aprovado em fevereiro de 2016.

\section{resumo/abstract/resumen}

\section{O discurso de Luiz Ruffato em Frankfurt: polêmica, recepção inicial e paradigmas em disputa}

Wanderlan da Silva Alves

Neste artigo, analisamos a configuração do discurso de abertura da Feira do Livro de Frankfurt de 2013, de Luiz Ruffato, abordando sua textualidade enquanto polêmica, bem como as tensões postas em circulação em sua recepção inicial. Procuramos demonstrar que tal discurso, em sua relação com a situação 
enunciativa e com o conjunto de disputas de territórios e lugares discursivos que ele desencadeou, funciona como um ato de fala que desvela a emergência de uma nova cultura no campo das artes em curso na literatura contemporânea no Brasil.

Palavras-chave: discurso crítico, literatura contemporânea, crítica literária contemporânea, Luiz Ruffato.

\section{Luiz Ruffato's speech in Frankfur: polemic, early reception and paradigms in dispute}

\section{Wanderlan da Silva Alves}

In this article, I analyze the construction of Luiz Ruffato's opening address for the 2013 Frankfurt Book Fair. I approach Ruffato's text as a polemic, and discuss some of the tensions generated by the speech's initial critical reception. I demonstrate that Ruffato's address - in relation with its enunciative context and the disputes around territories and discursive places that the event set in motion - becomes a speech act that reveals the emergence of a new culture in the artistic field that is taking place in contemporary Brazilian literature.

Keywords: critical speech, contemporary literature, contemporary literary critic, Luiz Ruffato.

\section{El discurso de Luiz Ruffato en Frankfurt: polémica, recepción inicial y paradigmas en disputa}

Wanderlan da Silva Alves

En este artículo analizamos la configuración del discurso del escritor brasileño Luiz Ruffato en la apertura de la Feria del Libro de Frankfurt de 2013, acudiendo a su textualidad en tanto polémica, amén de las tensiones asociadas con la recepción inmediatamente posterior a su lectura en la feria. Buscamos demostrar que dicho discurso, en su relación con la situación de enunciación y con el abanico de disputas de territorios y lugares discursivos que su puesta en escena ha desencadenado, actúa como acto de habla que apunta a la emergencia de una nueva cultura en el campo de las artes en curso en la literatura contemporánea en Brasil.

Palabras clave: discurso crítico, literatura contemporánea, crítica literaria contemporánea, Luiz Ruffato. 